\title{
Product Customization Via Starting Solutions
}

Andreas Herrmann, University of St. Gallen, Switzerland

Christian Hildebrand, University of St. Gallen, Switzerland

Gerald Häubl, University of Alberta, Canada

Three field and three lab studies show that partitioning consumer product customization processes into two stages - (1) choosing a "starting solution" and (2) refining that starting solution to create the final self-designed product - stimulates mental simulation of product use, promotes the choice of more feature-rich products, and enhances product satisfaction.

\section{[to cite]:}

Andreas Herrmann, Christian Hildebrand, and Gerald Häubl (2013),"Product Customization Via Starting Solutions", in NA Advances in Consumer Research Volume 41, eds. Simona Botti and Aparna Labroo, Duluth, MN : Association for Consumer Research.

[url]:

http://www.acrwebsite.org/volumes/1015503/volumes/v41/NA-41

\section{[copyright notice]:}

This work is copyrighted by The Association for Consumer Research. For permission to copy or use this work in whole or in part, please contact the Copyright Clearance Center at http://www.copyright.com/. 


\section{Product Customization Via Starting Solutions}

Christian Hildebrand, University of St. Gallen, Switzerland

Andreas Herrmann, University of St. Gallen, Switzerland

Gerald Häubl, University of Alberta, Canada

\section{EXTENDED ABSTRACT}

Product customization, whereby consumers self-design their products using a seller's mass customization (MC) interface, has the potential to provide consumers with offers that closely match their idiosyncratic preferences and, hence, to increase their product satisfaction, loyalty, and willingness-to-pay (Ansari \& Mela 2003; Franke et al. 2010). Recent research suggests that each of the two most common formats of product customization - (1) the "by alternative" format of having consumers choose from a pre-specified set of alternatives and (2) the "by attribute" format of asking consumers to customize every attribute and attribute level of the product - has distinct limitations from the consumer's perspective (Huffman \& Kahn 1998; Valenzuela et al. 2009), such as increased complexity due to tradeoffs among attributes (Valenzuela et al. 2009; Dhar 1997) and the need to process a large number of attribute information in parallel (Dellaert \& Stremersch 2005; Huffman \& Kahn 1998).

Inspired by prior research on multi-stage decision processes suggesting that consumers typically first narrow down the set of considered alternatives, and subsequently examine the remaining alternatives in greater depth (Beach 1993; Ge, Häubl, \& Elrod 2012; Häubl \& Trifts 2000, Bettman \& Park 1980), we propose a novel procedure that partitions the product customization process into two stages, whereby consumers first select one of a few pre-specified products as a starting solution, and then create their final customized product by further refining this starting solution. Our key hypotheses were that, compared to standard attribute-by-attribute MC systems, the proposed two-stage approach would reduce the cognitive effort associated with product customization, promote mental simulation of product use, motivate the purchase of more feature-rich - and thus higher-priced - products, and lead to greater satisfaction with selfdesigned products.

Converging evidence from a series of field and lab studies shows that, compared to standard (attribute-by-attribute) customization systems, the two-stage "Customization via Starting Solutions" procedure reduces decision complexity, promotes the mental simulation of product use, leads to the purchase of more feature-rich, higher-priced products, and results in greater customer satisfaction.

A field study with 842 customers of a large manufacturer of men's dress shirts revealed that, as predicted, consumers who used the two-stage MC format designed more feature-rich shirts than did those who used a standard attribute-by-attribute MC system, ultimately resulting in the choice of higher-priced products $\left(\mathrm{M}_{\text {Two- }}\right.$ $\left.{ }_{\text {Stage }}=€ 73.21, \mathrm{M}_{\text {Standard }}=€ 57.77 ; t(840)=3.245, p<.01\right)$. Moreover, the two-stage format significantly reduced the amount of time it took consumers to self-design their shirt relative to the manufacturer's standard MC system $\left(\right.$ Beta $\left._{\text {Two-Stage }}=-4.95, t(837)=3.25, \mathrm{p}<.01\right)$.

In a field experiment conducted with 159 car buyers at a major German automobile manufacturer's web site, we found that customers who had been randomly assigned to a two-stage rather than a standard (i.e., attribute-by-attribute) MC interface not only configured significantly more feature-rich cars as reflected by higher-priced configurations $\left(\mathrm{M}_{\text {Two-Stage }}=€ 20,765, \mathrm{M}_{\text {Standard }}=€ 18,349 ; t(158)=2.071\right.$, $p<.05$ ), but were ultimately also substantially more satisfied with their self-designed vehicle $(t(158)=2.14, p<.05)$ as revealed by a follow-up survey.
A field experiment at a ski resort in Switzerland in which 210 travelers were randomly assigned to either a standard customization system or the proposed two-stage format provided additional support for our hypotheses. As predicted, the proposed two-stage procedure caused travelers to select resort packages that included a greater number of services $\left(\mathrm{M}_{\mathrm{Two}-\mathrm{Stage}}=25.35, \mathrm{M}_{\text {Standard }}=16.80, t(209)=9.930, p\right.$ $<.001)$ and were higher priced $\left(\mathrm{M}_{\text {Two-Stage }}=\right.$ CHF1,611.96, $\mathrm{M}_{\text {Standard }}$ $=\mathrm{CHF} 1,061.46, t(209)=9.948, p<.001)$, ultimately resulting in greater satisfaction with their ski vacation $\left(\mathrm{M}_{\text {Two-Stage }}=6.11, \mathrm{M}_{\text {Stan- }}\right.$ dard $=5.74, t(209)=2.122, p<.05)$.

Three lab experiments, all involving a web-based jewelry customization interface, examined the psychological processes that underlie these effects. In the first of these experiments, 69 participants were randomly assigned to either a standard MC system or the proposed two-stage format. A multiple mediation model revealed that the positive effect of the two-stage format on consumers' satisfaction with their self-design products is mediated by an increase in their mental simulation of product use, as well as a decrease in the perceived complexity of the decision process $(\mathrm{z}=2.628, p<.01)$. A second lab experiment with 133 participants revealed that, compared to a standard MC system, using a two-stage procedure caused a significantly lower error rate in a Stroop task $\left(\mathrm{M}_{\text {Two-Stage }}=1.23, \mathrm{M}_{\text {Standard }}\right.$ $=2.30, t(132)=2.458, p<.05)$, indicating greater availability of cognitive resources after self-designing a product using the two-stage format.

The third lab experiment was designed to examine the effect of merely allowing consumers to refine their initial product choice, without at the same time identifying a subset of the possible product configuration as candidate starting solutions. A total of 100 participants were randomly assigned to either a standard MC system or a two-stage format. In the latter condition, the set of starting solutions was, in fact, the entire assortment of all possible combinations of attribute levels that consumers could configure in the standard MC condition. In line with our prediction, participants in the two-stage condition were significantly more satisfied with their ultimate selfdesigned product $\left(\mathrm{M}_{\text {Two-Stage }}=6.33, \mathrm{M}_{\text {Standard }}=5.92, t(100)=2.577, p<\right.$ .01 ), and this effect was mediated by an increase in mental simulation of product use and a reduction in the perceived complexity of the self-design process $(\mathrm{z}=2.537, p<.05)$.

This paper's contribution to the literature is threefold: First, it shows that the two-stage format outperforms current customization formats, resulting in increased consumer satisfaction with self-designed products. Second, this research reveals that the proposed selfdesign format stimulates consumers' mental simulation of product use, which in turn results in the choice of more feature-rich products. Finally, it highlights the external validity and generalizability of the key conceptual insights by presenting converging evidence from lab experiments and field studies involving actual purchases in a various domains.

\section{REFERENCES}

Ansari, A. \& C. F. Mela (2003). E-Customization. Journal of Marketing Research, 40(May), 131-145.

Beach, L. R. (1993). Broadening the Definition of Decision Making: The Role of Prechoice Screening of Options. Psychological Science, 4(4), 215-220. 


\section{2 / Product Customization Via Starting Solutions}

Bettman, J. R. \& C. W. Park (1980). Effects of Prior Knowledge and Experience and Phase of the Choice Process on Consumer Decision Processes: A Protocol Analysis. Journal of Consumer Research, 7(December), 234-248.

Dhar, R. (1997). Consumer Preference for a No-Choice Option. Journal of Consumer Research, 24(September), 215-231.

Dellaert, B. G. \& S. Stremersch (2005). Marketing MassCustomized Products: Striking a Balance between Utility and Complexity. Journal of Marketing Research, 42(2), 219-227.

Franke, N., M. Schreier \& U. Kaiser (2010). The "I Designed It Myself" Effect in Mass Customization. Management Science, 56(1), 125-140.

Ge, X., G. Häubl, \& T. Elrod (2012). What to Say When: Influencing Consumer Choice by Delaying the Presentation of Favorable Information, Journal of Consumer Research, 38(6), 1004-1021.

Häubl, G. \& V. Trifts (2000). Consumer Decision Making in Online Shopping Environments: The Effects of Interactive Decision Aids. Marketing Science, 19(1), 4-21.
Huffman, C. \& B. E. Kahn (1998). Variety for Sale: Mass Customization or Mass Confusion? Journal of Retailing, 74 (4), 491-513.

Stroop, J. R. (1935). Studies of interference in serial verbal reactions. Journal of Experimental Psychology, 18(6), 643-662.

Thaler, R. (1985). Mental accounting and consumer choice. Marketing Science, 4(3), 199-214.

Valenzuela, A., R. Dhar \& F. Zettelmeyer (2009). Contingent Response to Self-Customization Procedures: Implications for Decision Satisfaction and Choice. Journal of Marketing Research, 46(6), 754-763.

Zhao, M., S. Hoeffler \& G. Zauberman (2011). Mental Simulation and Product evaluation: the affective and Cognitive Dimensions of Process versus outcome Simulation. Journal of Marketing Research, 68(October), 827-839. 